\title{
Caesarean Scar Ectopic Pregnancies-Case Series from a District General Hospital
}

\author{
Folasade Akhanoba*, Alero Awala, Tony Boret \\ Watford General Hospital, West Hertfordshire Hospitals NHS Trust, Hertfordshire, UK \\ Email: *folasadeolanrewaju@gmail.com
}

How to cite this paper: Akhanoba, F. Awala, A. and Boret, T. (2017) Caesarean Scar Ectopic Pregnancies-Case Series from a District General Hospital. Open Journal of Obstetrics and Gynecology, 7, 608-615. https://doi.org/10.4236/ojog.2017.75063

Received: April 5, 2017

Accepted: May 23, 2017

Published: May 26, 2017

Copyright $\odot 2017$ by authors and Scientific Research Publishing Inc. This work is licensed under the Creative Commons Attribution International License (CC BY 4.0).

http://creativecommons.org/licenses/by/4.0/

(c) (i) Open Access

\begin{abstract}
Caesarean Scar Ectopic Pregnancy (CSEP) is a rare, but potentially catastrophic complication of a previous Caesarean Section (CS) birth. This is a review of 5 cases of CSEP managed in our Early Pregnancy Unit at Watford General Hospital within a 10-month period. Two patients had only one previous CS, whilst 2 had two and the last had 3 previous CS. All our patients presented within the first trimester of pregnancy (range 6 to 11 weeks' gestation) with light vaginal bleeding; 4 of them had associated mild to moderate abdominal pain. All were diagnosed using transvaginal ultrasound scan. Three of our patients were managed surgically by Suction Evacuation under Ultrasound guidance and insertion of a Foley's catheter prophylactically for tamponade in order to reduce blood loss both intra- and post-operatively. One of our patients had a heterotopic pregnancy with a viable intrauterine pregnancy and a live CSEP. She declined any intervention so she was managed conservatively with weekly Consultant appointments and scans. There was a subsequent demise of the CSEP and she continued with a singleton pregnancy. None of our patients were managed medically. There is no absolute consensus on diagnostic criteria and there is no standard management protocol so each woman should be given all the available information and the opportunity to decide on the management of her pregnancy. The risk of a CSEP in a subsequent pregnancy should be part of the consent process for CS.
\end{abstract}

\section{Keywords}

Caesarean Scar Ectopic Pregnancy

\section{Introduction}

The first case of a Caesarean Scar Ectopic Pregnancy (CSEP) was reported in English medical literature in 1978 [1]. Over the years, there has been an increase in the number of publications about CSEPs (Figure 1). This may reflect a 
"true" increase in its incidence because of the rising caesarean section rate or an "apparent" one as result of better detection of the CSEP [2]. CSEP now has an estimated incidence of 1 in 2226 pregnancies [3]. A CSEP results when an embryo implants in a previous Caesarean Section (CS) fibrous tissue scar. The damage to the decidua basalis during a CS persists in the endometrium in the form of tiny wedge defects. This defect forms a tract between the endometrial canal and the CS scar through which the embryo can invade the myometrium [4]. The gestation sac is therefore completely surrounded by myometrium and the scar tissue, and totally separate from the endometrial cavity [2].

As part of the consent process prior to a CS, patients are informed about the risks of placental pathologies in subsequent pregnancies. However, a discussion specifically about the risk of CSEP is often not a part of this consent process; despite the fact that a CSEP is considered to be even more aggressive than placenta accreta because of its myometrial invasion in the first trimester, with even more catastrophic sequelae if the CSEP is to continue into the second or third trimester [2]. We present 5 cases of CSEPs that we managed in our Early Pregnancy Unit at Watford General Hospital within a 10-month period.

\section{Case Series}

NP was a 40 -year-old woman with one CS 5 years ago for suspected fetal distress who presented to us at 10 weeks of pregnancy with light vaginal bleeding and abdominal pain. Her $\beta$-hCGwas 2996 (normal range for her gestational age is $18,700-244,467$ ) with a progesterone level of 9.1 (reference range 11 to 81 ). An initial scan queried a CSEP or a miscarriage. The CSEP was confirmed by a second scan 5 days later after suboptimal $\beta$-hCG changes from 2996 to 210448 hours later. The scan revealed an empty uterus and an irregular area containing mixed echogenic material measuring $31 \times 28 \times 30 \mathrm{~mm}$ close to the CS scar (Figure 2). After counselling, NP underwent Hysteroscopy and Ultrasound guided Suction Evacuation of the CSEP. A foley catheter was inserted into the cervical canal for tamponade and haemostasis. She lost $100 \mathrm{mls}$ of blood intra-operatively, had an uneventful recovery and was discharged on the same day after removal of the foley catheter. She remained well at follow-up a week later and histology of the products of conception revealed non-molar chorionic villi and decidua.

YB, a 33-year-old woman with two previous CS (the first was an emergency and the second was elective), presented to us with 11 weeks' amenorrhoea, light vaginal bleeding and abdominal cramps. Her $\beta$-hCG was 3797 (normal range for her gestational age is $23,143-181,899$ ) with a progesterone level of 10.1. A scan revealed an empty cervical canal, an irregular empty gestation sac measuring 18 $\times 9 \times 17 \mathrm{~mm}$ developing within the anterior part of the lower uterine segment and thinning of the myometrium between the gestation sac and bladder to 4.1 $\mathrm{mm}$ (Figure 3). The patient was offered either medical management with methotrexate or surgical management by Ultrasound guided Uterine Curettage. She opted for surgery and had a balloon catheter inserted for tamponade which was removed prior to discharge. She had a blood loss of $200 \mathrm{ml}$, an uncomplicated 


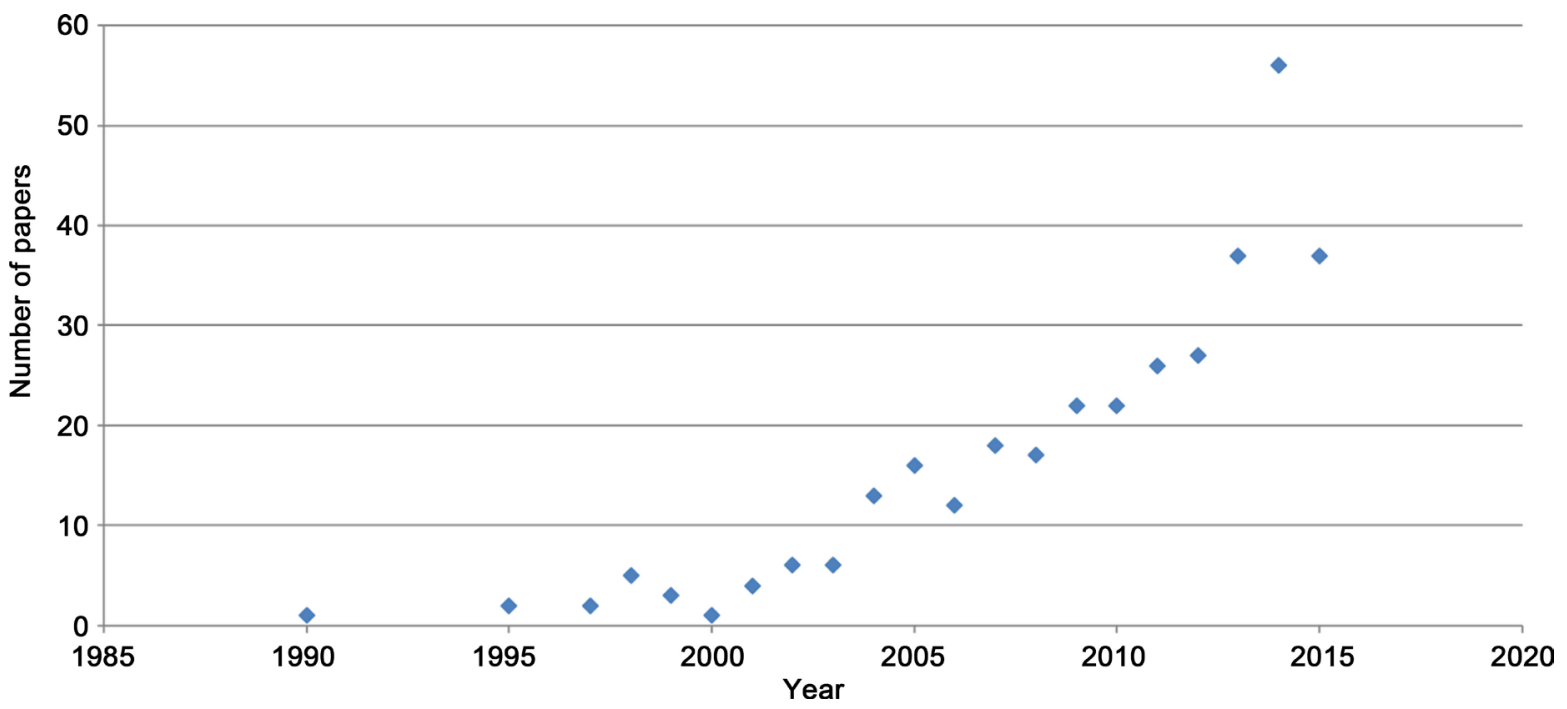

Figure 1. Over the years, there has been an increase in the number of publications about CSEPs.

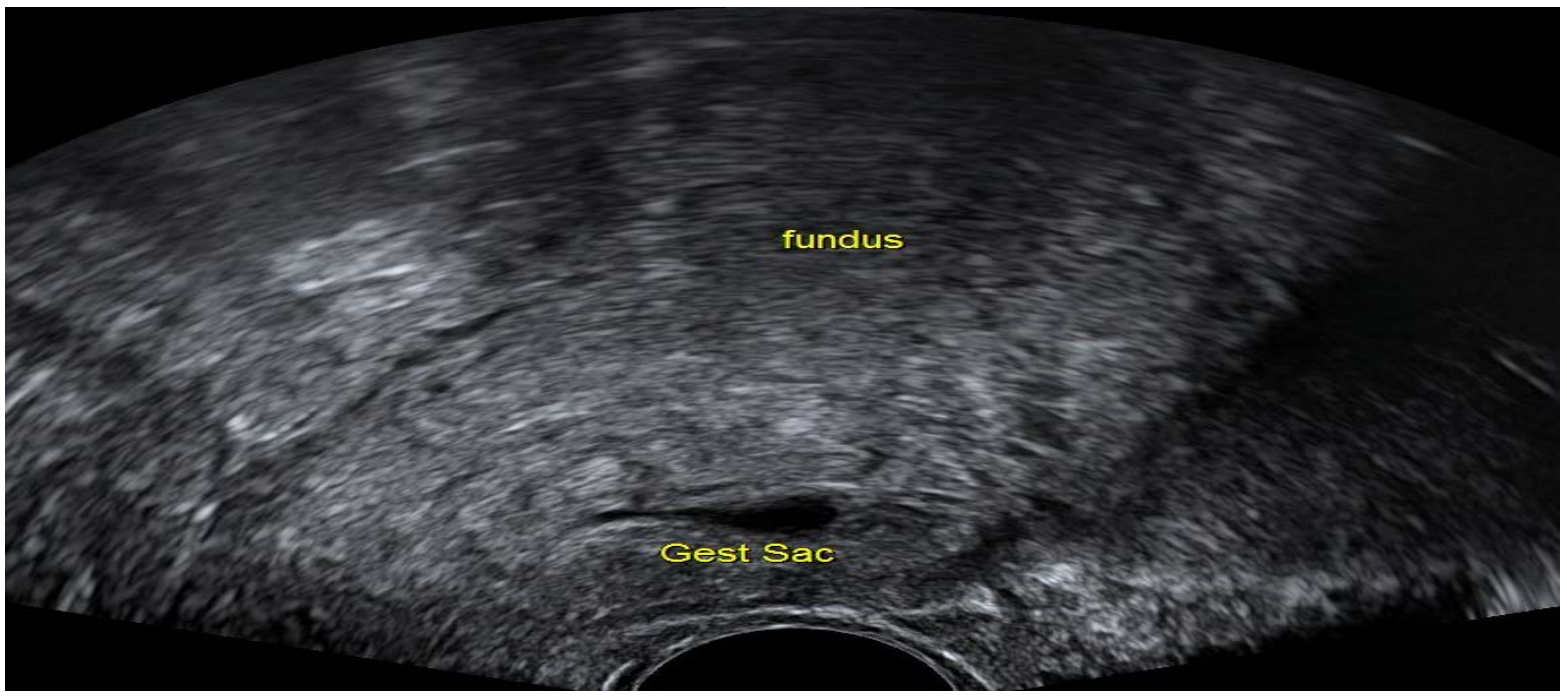

Figure 2. An irregular gestation sac within the previous CS scar in a sagittal view of the uterus.

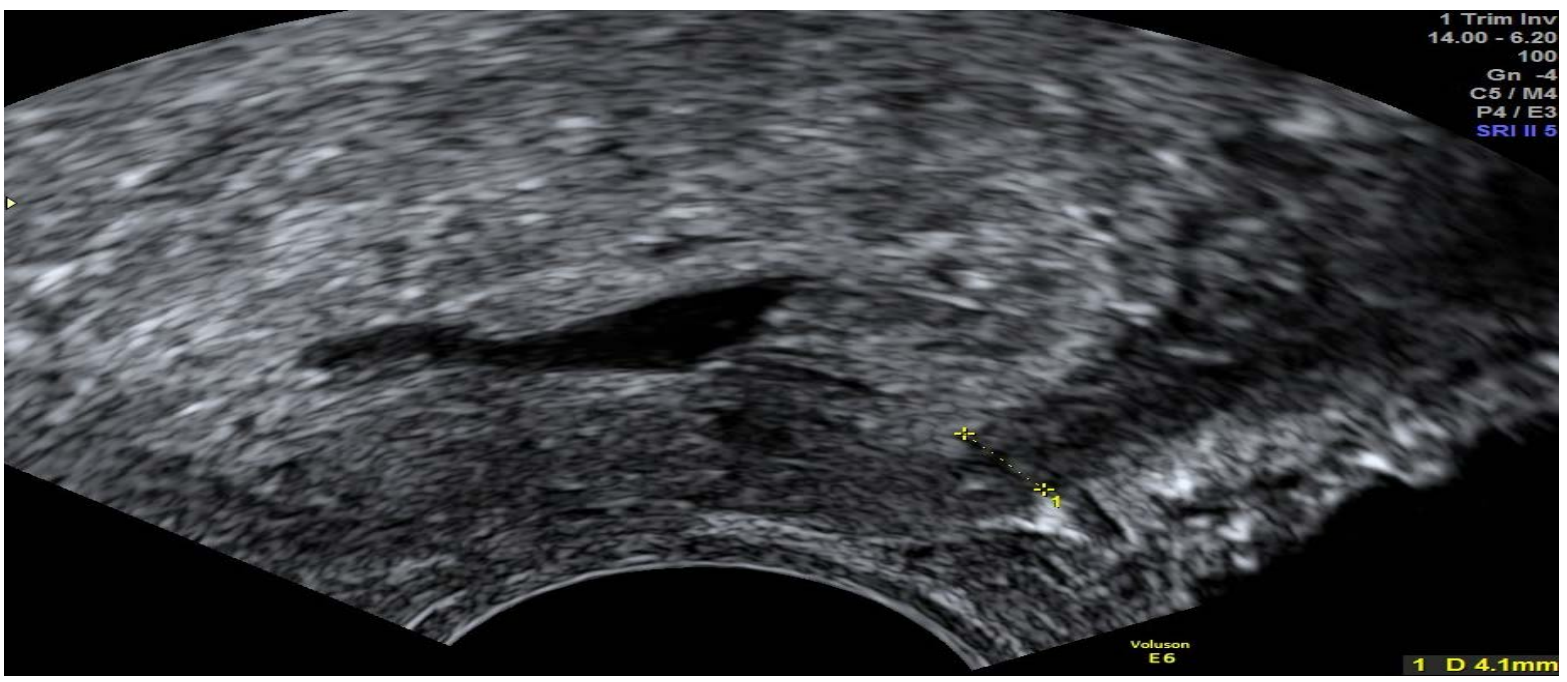

Figure 3. A sagittal view of the uterus showing thinning of the myometrium between the gestation sac and bladder to $4.1 \mathrm{~mm}$. 
recovery period and was discharged home after 24 hours.

$\mathrm{AH}$ was a 34-year-old woman who had had one CS and presented at 7 weeks of pregnancy with vaginal bleeding. Her $\beta$-hCG was 33,096 (normal range for her gestational age is 8636 - 218,085) and her progesterone was 39.8. A scan revealed a $41 \times 12 \times 16 \mathrm{~mm}$ gestation sac embedded in her CS scar (Figure 4). Within the sac was a live fetal pole with a Crown Rump Length of $5 \mathrm{~mm}$. There was a small area of bleed measuring $18 \times 9 \times 10 \mathrm{~mm}$ adjacent to the sac. She was referred to the Early Pregnancy Unit at a Tertiary Centre in London where the live CSEP was confirmed. The patient, however, travelled to Australia and was lost to follow-up.

KAP, a 29-year-old lady with a background of 3 previous CS (two as an emergency for failure to progress and the third was elective) and surgical management for a miscarriage, presented with vaginal bleeding and mild abdominal pain at 6 weeks of pregnancy.A scan revealed a twin pregnancy with a live CSEP and a live intra-uterine pregnancy with a subchorionic bleed (Figure 5). After extensive counselling about the options available to her, including termination of the pregnancy versus regular scanning to monitor the progress of the CSEP closely, the patient opted for conservative management. She was rescanned a week later at 7 weeks' gestation and both twins remained viable. She was then referred to a Tertiary Centre in London for a second opinion where she was scanned again one week later. This scan at 8 weeks' gestation revealed a normal appearance for twin one. The second gestation sac remained implanted in the CS scar and although the sac was now irregular in shape, the fetus maintained its heartbeat. A week later, a scan at 9 weeks' gestation demonstrated that twin one remained viable with appropriate growth since the previous scan, but there was a demise of twin two with a collapsing gestation sac. At her scan two weeks later at 11 weeks' gestation, the intra-uterine pregnancy continued to progress normally and the collapsing sac persisted at the level of the CS scar. Her anomaly scan at 20 weeks' gestation showed normal fetal growth and liquor volume, with an anterior placenta which was clear of the cervical os. The second sac at the level of the CS scar could no longer be seen. KAP remained under Consultant-led antenatal care until she presented at 38 weeks' gestation with abdominal pain and bleeding and underwent an emergency CS for placental abruption. She lost 2 litres of blood, but then had an uneventful recovery period. Both mother and baby remain well.

SF is a 28-year-old who presented at 7 weeks of pregnancy with left iliac fossa pain and light vaginal bleeding. Her two children were born by emergency CS for slow progress in labour. On examination, she had lower abdominal tenderness and she was tachycardic, with a heart rate of $114 \mathrm{bpm}$, so she was admitted for closer observation. Her $\beta$-hCG was 33,197 (normal range for her gestational age is 8636 - 218,085) and a scan the following day revealed a gestation sac extending from the fundus, down the endometrial cavity and attached to the CS scar (Figure 6). Within the sac was a viable fetal pole. A repeat scan by a Consultant confirmed a CSEP and after extensive counselling, SF opted for 


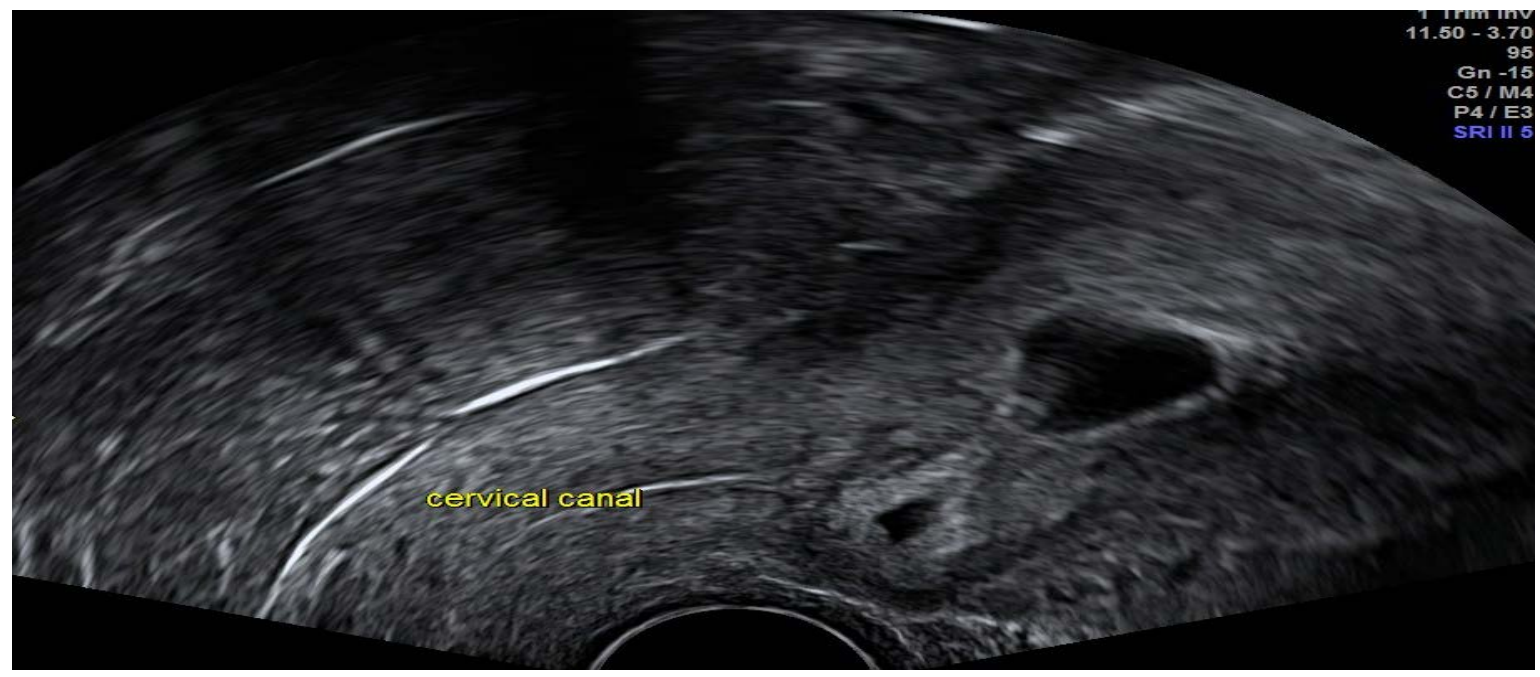

Figure 4. A sagittal views of the uterus with the gestation sac embedded in the CS scar. The cervical canal is empty.

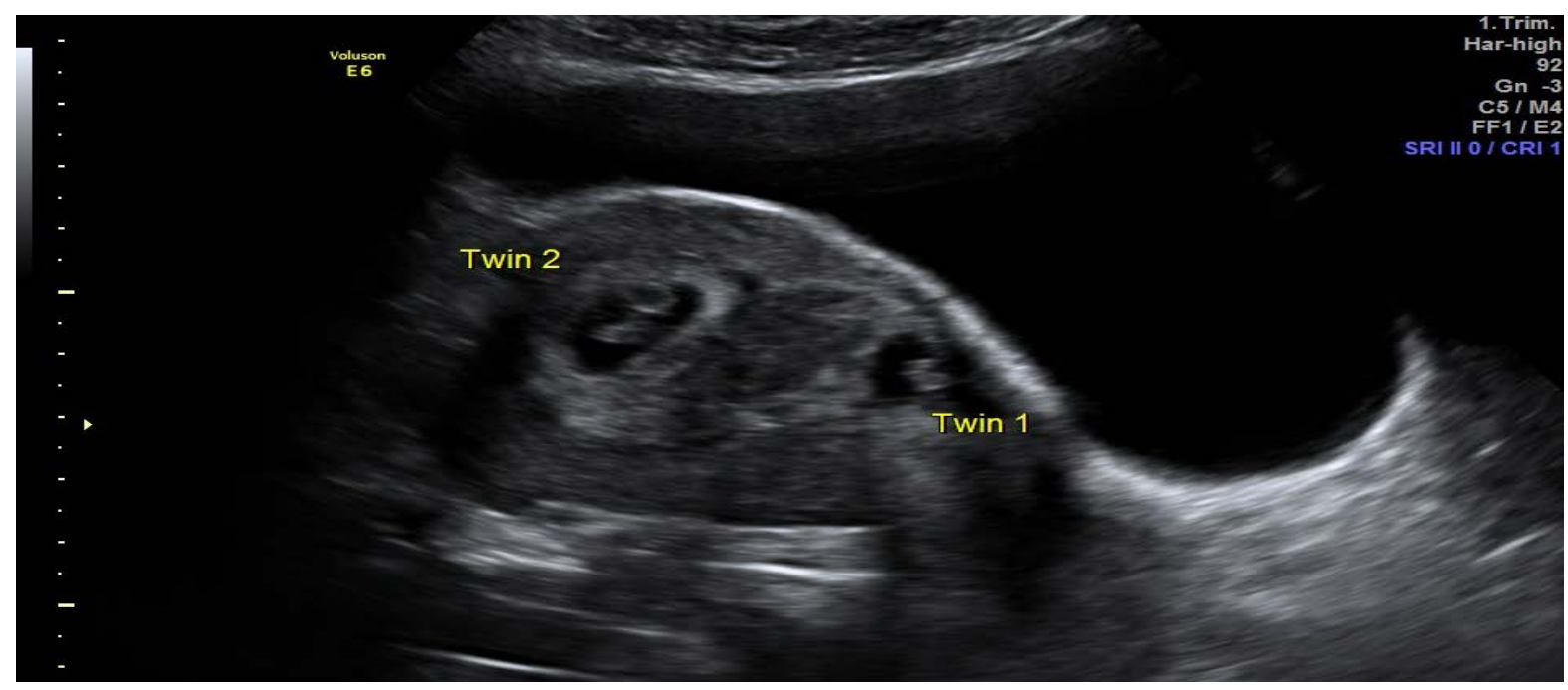

Figure 5. A sagittal view of the uterus demonstrating a heterotopic pregnancy (a CSEP and an intra-uterine pregnancy).

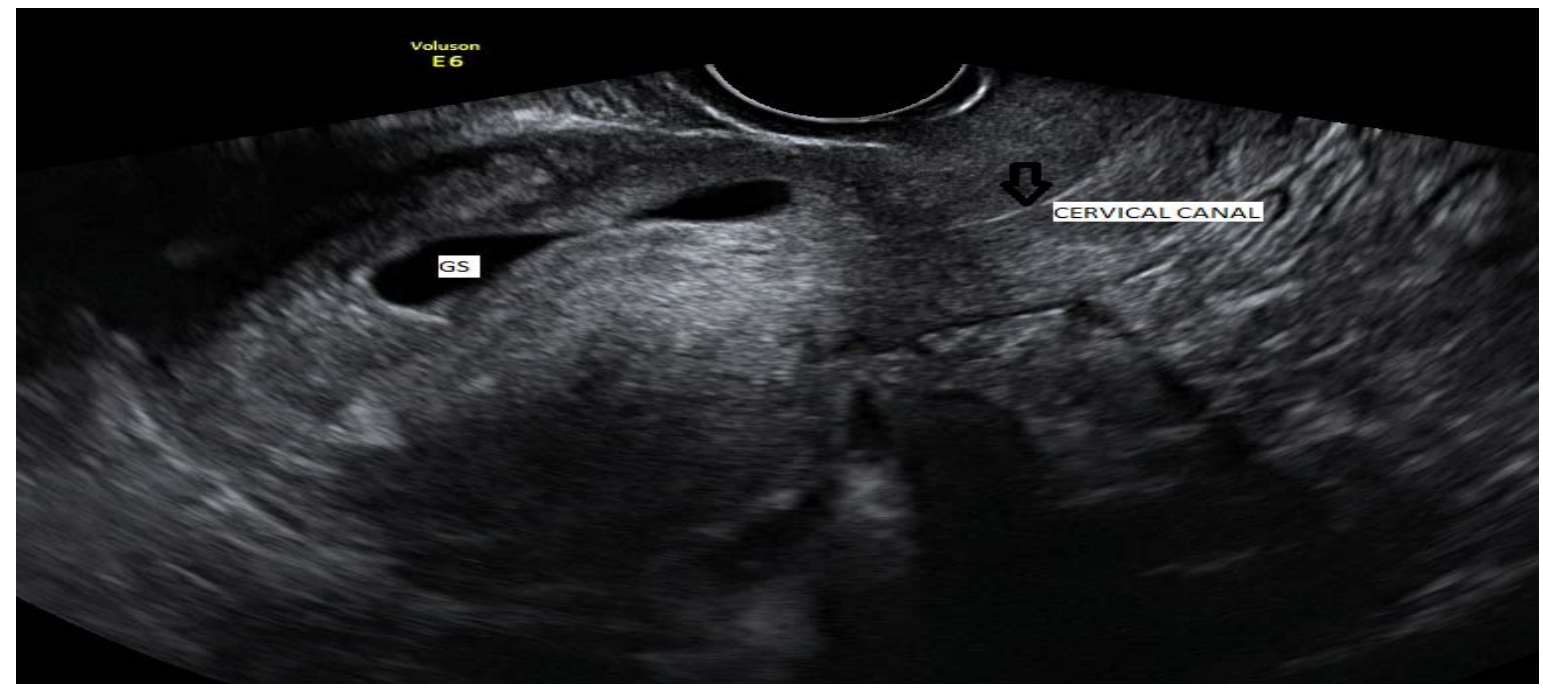

Figure 6. A sagittal view of the uterus with an irregular empty gestation sac developing within the anterior part of the lower uterine segment. The uterine cavity and cervical canal are empty. 
Suction Evacuation of the CSEP under Ultrasound guidance. She lost $100 \mathrm{mls}$ of blood, and apart from initially having difficulty passing urine which required the insertion of a temporary urinary catheter, she had an uneventful recovery.

\section{Discussion}

All our patients presented within the first trimester of pregnancy (range 6 to 11 weeks gestation). We know from literature that CSEPs may present from as early as 5 to 6 weeks to as late as 16 weeks' gestation [5]. Clinical presentation varies from light, painless vaginal bleeding (39\% of cases), but the bleeding may also be associated with mild to moderate pain (16\% of cases) [6], as was the case with our patients. Nine percent of patients will present with only abdominal pain, whilst $37 \%$ will be completely asymptomatic [5], hence the need for a high index of suspicion whilst scanning patients who have had a previous CS. $\beta$-hCG levels ranged from 2996 to 33,197, with higher levels being associated with live CSEP. Our patients were mostly haemodynamically stable, allowing time for adequate investigation so we were able to confirm all cases by ultrasound scan. Transvaginal ultrasound scan (TVS) has a diagnostic sensitivity of $84.6 \%$ [5]. There is no absolute consensus on diagnostic criteria, but generally these should include an empty uterus and cervical canal, hence ruling out an intrauterine pregnancy or miscarriage and a cervical ectopic pregnancy. It is important to note that when the gestational sac, with or without an embryo, is only partially implanted into the CS scar, it can extend into the uterine cavity. However, it should still be located in the anterior part of the lower uterine segment and there will be a thinning of the myometrium between the bladder wall and the gestational sac [7]. The myometrial thickness has been shown to be less than $5 \mathrm{~mm}$ in twothirds of the cases [2]. We demonstrated these features prior to diagnosing the CSEP in each case. To improve the diagnostic sensitivity of the TVS, colour flow Doppler can be applied to demonstrate the peritrophoblastic flow around the gestation sac, and its relationship to the CS scar and proximity to the bladder [2]. For cases where the TVS combined with colour flow Doppler is still inconclusive, Magnetic Resonance Imaging (MRI) scan can be used [2].

The decision on management is naturally easier when the pregnancy is not viable. The reality is that very few of these pregnancies progress beyond the first trimester as almost all are terminated during this period [8]. A review of the literature demonstrates that when a CSEP continues into the second or third trimesters, there is a substantial risk of uterine rupture with catastrophic haemorrhage and a high risk of hysterectomy [2] [5]. The danger of bladder invasion by the developing placenta also increases the risk of urinary tract injury. Some of these pregnancies will continue as an intrauterine pregnancy, but the risk of placenta accreta is increased by up to three- to five-fold [2].

As with the diagnostic criteria, there is also no consensus on the preferred mode of treatment. Nevertheless, the ideal treatment option should be technically simple with minimal complications; and should aim to remove the gestation sac prior to uterine rupture, reduce the risk of recurrence and retain the pa- 
tient's future fertility [2]. Management options include expectant, medical and surgical. Three of our patients were managed surgically with no complication. In our Unit, we manage our patients by Suction Evacuation under Ultrasound guidance and often insert a foley catheter prophylactically for tamponade after the procedure in order to reduce blood loss both intra- and post-operatively. Other surgical management options for the CSEP include primary open resection, laparoscopic removal and hysteroscopic evacuation. CSEPs were initially managed via laparotomy and wedge resection of the lesion (primary open resection) after it was described by Larsen et al. in 1978 [1]. This is still the preferred option in haemodynamically unstable women when uterine rupture is confirmed or suspected. Laparoscopic removal was later described in 1999 by Lee et al. [9] and is most suitable for deeply implanted CSEPs growing toward the abdominal cavity and bladder. For CSEPs growing inwards toward the uterine cavity, hysteroscopic evacuation is most appropriate. It was described in 2005 by Wang et al. [10] and should only be performed after the diagnosis has been confirmed.

Interestingly, despite its success rate of 71 to 80 percent [7], none of our patients were managed medically. Medical management generally involves either the systemic or local administration of methotrexate, or a combination of both [2]. As with other ectopic pregnancies, for a woman to qualify for the systemic medical approach, she should be pain free, haemodynamically stable with an unruptured CSEP of less than 8 weeks' gestation and ideally $\beta$-hCG levels should be less than 5000 . The local administration of methotrexate is done under ultrasound guidance and is suitable even with a live CSEP and $\beta$-hCG levels above 5000. Other agents such as potassium chloride, hyperosmolar glucose and crystalline trichosanthin have also been used for local injection [2]. Patients should be made aware of the potential for prolonged bleeding as the CSEP may take over a year to resolve, and the need for follow-up in view of the risk of sudden haemorrhage, leading to a six percent risk of hysterectomy after medical management [8].

Expectant management is most suitable for failed CSEPs, especially when they are inaccessible or small. It is naturally also the only option for women who decline any intervention, as was the case with our lady who was diagnosed with the heterotopic pregnancy. Women being managed conservatively require appropriate counselling by senior members of the team and need to be aware of the need for frequent follow-up [2]. Our lady had weekly Consultant appointments and scans, and fortunately there was a subsequent demise of the CSEP and she continued with a singleton pregnancy.

CSEP is a rare, but potentially catastrophic complication of a previous CS birth. Needless to say, this is yet another reason to be even more proactive about reducing our primary CS rates. Unfortunately, there is a lack of significant data and no standard management protocol, so each woman should be given all the available information and the opportunity to decide on the management of her pregnancy. Irrespective of her decision, she should be supported every step of the way. The available evidence shows that the prognosis for an uneventful term 
pregnancy is very poor [2] [7] and therefore termination of such a pregnancy, once the correct diagnosis is made, is often recommended. Nevertheless, as we discussed earlier, some of these pregnancies will continue as an intrauterine pregnancy so there should be absolute diagnostic certainty prior to offering any woman a termination of a wanted pregnancy. If required, cases should be referred to tertiary centres who manage CSEPs more frequently. Lastly, the increase in the incidence of these cases means it might be appropriate to inform women of the risk of a CSEP in a subsequent pregnancy when taking consent for a CS.

\section{Conflict of Interests}

All authors agree with the content of the manuscript and there are no conflicts of interests between them.

\section{References}

[1] Larsen, J.V. and Solomon, M.H. (1978) Pregnancy in a Uterine Scar Sacculus: An Unusual Cause of Postabortal Haemorrhage. South African Medical Journal, 53, 142-143.

[2] Ash, A., Smith, A. and Maxwell, D. (2007) Caesarean Scar Pregnancy. BJOG, 114, 253-263. https://doi.org/10.1111/j.1471-0528.2006.01237.x

[3] Seow, K.-M., Huang, L.-W., Lin, Y.H., Yan, S., Lin, M., Tsai, Y.-L. and Hwang, J.-L. (2004) Caesarean Scar Pregnancy: Issues in Management. Ultrasound in Obstetrics \& Gynecology, 23, 247-253. https://doi.org/10.1002/uog.974

[4] Godin, P.-A., Bassil, S. and Donnez, J. (1997) An Ectopic Pregnancy Developing in a Previous Caesarean Section Scar. Fertility and Sterility, 67, 398-400.

[5] Smith, A., Maxwell, D. and Ash, A. (2007) Sonographic Diagnosis of Caesarean Scar Pregnancy at 16 Weeks. Journal of Clinical Ultrasound, 35, 212-215. https://doi.org/10.1002/jcu.20270

[6] Rotas, M.A., Haberman, S. and Levgur, M. (2006) Cesarean Scar Ectopic Pregnancies: Etiology, Diagnosis and Management. Obstetrics \& Gynecology, 107, 1373 1377. https://doi.org/10.1097/01.AOG.0000218690.24494.ce

[7] Vial, Y., Petignat, P. and Hohlfeld, P. (2000) Pregnancy in a Caesarean Scar. Ultrasound in Obstetrics \& Gynecology, 16, 592-593. https://doi.org/10.1046/j.1469-0705.2000.00300-2.x

[8] Jurkovic, D., Hillaby, K., Woelfer, B., Lawrence, A., Salim, R., et al. (2003) First Trimester Diagnosis and Management of Pregnancies Implanted into the Lower Uterine Segment Cesarean Section Scar. Ultrasound in Obstetrics \& Gynecology, 21, 220-227. https://doi.org/10.1002/uog.56

[9] Lee, C.L., Wang, C.J., Chao, A., Yen, C.F. and Soong, Y.K. (1999) Laparoscopic Management of an Ectopic Pregnancy in a Previous Caesarean Section Scar. Human Reproduction, 14, 1234-1236. https://doi.org/10.1093/humrep/14.5.1234

[10] Wang, C.-J., Yuen, L.-T., Chao, A.-S., Lee, C.-L., Yen, C.-F. and Soong, Y.-K. (2005) Caesarean Scar Pregnancy Successfully Treated by Operative Hysteroscopy and Suction Curettage. BJOG, 112, 839-840. 
Submit or recommend next manuscript to SCIRP and we will provide best service for you:

Accepting pre-submission inquiries through Email, Facebook, LinkedIn, Twitter, etc. A wide selection of journals (inclusive of 9 subjects, more than 200 journals)

Providing 24-hour high-quality service

User-friendly online submission system

Fair and swift peer-review system

Efficient typesetting and proofreading procedure

Display of the result of downloads and visits, as well as the number of cited articles Maximum dissemination of your research work

Submit your manuscript at: http://papersubmission.scirp.org/

Or contact ojog@scirp.org 